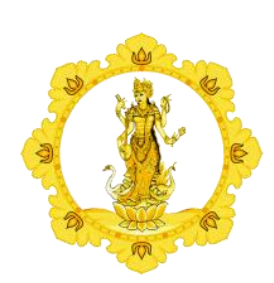

KALANGWAN

JURNAL PENDIDIKAN AGAMA, BAHASA DAN SASTRA

Vol. 11 No. 2 September 2021

\begin{tabular}{l|l|l|}
\hline p-ISSN : 1979-634X & e-ISSN : 2686-0252 & http://ejournal.ihdn.ac.id/index.php/Kalangwan \\
\hline
\end{tabular}

\title{
PENGARUH PENGGUNAAN CAMPUR KODE DALAM BERTUTUR BAHASA INDONESIA TERHADAP IDENTITAS BANGSA
}

\author{
Oleh : \\ Nenden Nur Intan ${ }^{1)}$, Supriyono ${ }^{2)}$, Dadi Mulyadi Nugraha ${ }^{3)}$ \\ 1)2)3) Universitas Pendidikan Indonesia

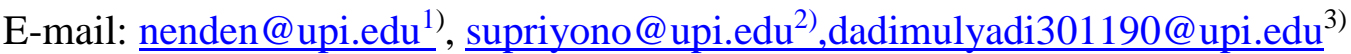

Diterima 02 Juli 2021, direvisi 11 Agustus 2021, diterbitkan 31 September 2021

\begin{abstract}
Abstrak
Penelitian ini bertujuan untuk mengetahui bagaimana pengaruh penggunaan campur kode dalam bertutur bahasa Indonesia terhadap identitas bangsa dengan menggunakan metode deskripsi kualitatif. Strategi yang digunakan adalah analisis isi, yaitu menganalisis hasil dokumen yang diberikan oleh responden mengenai tindak tutur campur kode terhadap identitas bangsa. Teknik pengumpulan data dilakukan dengan cara membagikan kuisioner melalui media google formulir kepada responden. Hasil penelitian ini menunjukkan bahwa masih banyak masyarakat Indonesia yang menggunakan campur kode dalam bertutur bahasa Indonesia. Biasanya ciri menonjolnya berupa situasi informal dan bisa juga terjadi karena keterbatasan bahasa yang tidak ada padanannya, sehingga ada keterpaksaan memasukkan unsur bahasa lain dalam tuturannya. Dari hasil penelitian, dinyatakan ada beberapa faktor terjadinya campur kode, di antaranya 1) Terjadi secara spontan. Hal tersebut bisa terjadi dikarenakan faktor lingkungan yang sering menggunakan campur kode, kemudian tanpa sadar diikuti. 2) Sudah menjadi kebiasaan. Masyarakat bilingual yang terbiasa menggunakan dua bahasa akan tanpa sadar mencampurkan dua unsur bahasa menjadi satu, hal tersebut terus berulang, sehingga menjadi kebiasaan. 3) Sulit menemukan arti bahasa Asing dalam bahasa Indonesia. Jika campur kode terjadi karena memang seseorang memiliki keterbatasan bahasa, ungkapan dalam bahasa tersebut tidak ada padanannya, sehingga ada keterpaksaan memasukkan unsur bahasa lain, maka itu adalah hal yang wajar. Tetapi, lain halnya jika mengikuti pergaulan tanpa mementingkan identitas dari bahasa Indonesia itu sendiri, maka bahasa Indonesia semakin lama akan semakin memudar dan akan mengikis identitas nasional. Oleh karena itu, kita harus menjaga bahasa Indonsia agar jati diri bangsa Indonesia tidak luntur.
\end{abstract}

Kata Kunci : Campur Kode, Sosiolinguistik, Identitas Bangsa 


\section{PENDAHULUAN}

Bahasa Indonesia digunakan di Negara Republik Indonesia dengan kedudukan sebagai bahasa nasional dan bahasa negara. Sebagai bahasa nasional, bahasa Indonesia memiliki fungsi sebagai identitas nasional dan alat pemersatu bangsa. Sedangkan, sebagai bahasa negara, bahasa Indonesia memiliki fungsi menjadi bahasa resmi kenegaaan, bahasa pengantar pendidikan, alat pengembangan ilmu pengetahuna dan teknologi serta alat pengembangan kebudayaan (Nugroho, 2015: 285). Sejalan dengan itu, Finegan (2004: 27) menyatakan bahwa terdapat pengertian dasar bahasa terbagi menjadi dua, yaitu bahasa sebagai suatu sistem yang kompleks dan bahasa adalah sebuah lambang yang bersifat arbitrer (manasuka).

Ciri atau identitas suatu kelompok masyarakat salah satunya bisa dilihat dari bahasanya. Fenomena penggunaan bahasa Indonesia banyak terjadi dewasa ini, salah satunya penggunaan campur kode dalam bertutur bahasa Indonesia. Bilingualisme, diglossia, interferensi, integrasi, konvergensi, alih kode, campur kode dan pergeseran bahasa adalah peristiwa-peristiwa kebahasaan sebagai akibat dari kontak bahasa yang mungkin terjadi (Chaer dan Agustina, 2010: 84). Selaras dengan hal tersebut, Rahardi (2011: 3) menyatakan bahwa dalam bidang bahasa, akibat dari peristiwa-peristiwa bahasa tersebut dapat mengakibatkan bervariasinya kode-kode yang dimiliki dan dikuasai oleh masyarakat. Kemajemukan masyarakat dalam bidang bahasa dapat dilihat dari banyaknya individu multilingual; mampu menguasai banyak bahasa atau sedikitnya bilingual; mampu menguasai dan menggunakan dua bahasa. Masyarakat dwibahasa ini dapat menguasai lebih dari satu bahasa, misalnya bahasa daerah (bahasa Sunda), bahasa pertama (bahasa Indonesia) dan bahasa asing (bahasa Inggris, Korea, Prancis, Arab, Jepang, Cina). Masyarakat dwibahasa ini mengakibatkan adanya campur kode dalam tuturannya. Campur kode yang dimaksud di sini adalah tindak tutur melibatkan dua orang yang menggunakan kode A (seperti bahasa Indonesia) dan terjadi penyisipan unsur bahasa lain (seperti bahasa asing) menggunakan kode B. Penggunaan campur kode ini disebabkan oleh persamaan latar belakang bahasa, sehingga cenderung menggunakan bahasa Indonseia dan mencampurnya dengan bahasa lain. Selain itu, ada beberapa faktor lainnya yang menyebabkan campur kode ini, di antaranya terjadi secara spontan, sudah menjadi kebiasaan dan sulit menemukan arti bahasa daerah atau bahasa asing dalam bahasa Indonesia. Fenomena tersebut sangat menarik untuk diteliti karena bahasa Indonesia merupakan salah satu identitas bangsa dan jika bahasa Indonesia pudar, maka identitas bangsa pun akan ikut memudar. Artikel ini akan memberikan paparan tentang pengaruh penggunaan campur kode dalam bertutur bahasa Indonesia terhadap identitas bangsa.

\section{METODE}

Penelitian dilakukan pada tanggal 9-11 Maret 2021. Penelitian ini menggunakan metode penelitian deskripsi kualitatif yaitu berusaha untuk menggambarkan dan menginterpretasikan secara objektif. Penelitian ini menggunakan strategi analisis isi, yaitu menganalisis hasil dokumen yang diberikan oleh responden mengenai tindak tutur campur kode terhadap identitas bangsa. Teknik pengumpulan data dilakukan dengan cara membagikan kuisioner melalui media google formulir kepada responden.

\section{PEMBAHASAN \\ a. Campur Kode}

Menurut Kamus Besar Bahasa Indonesia (KBBI), campur kode merupakan penggunaan satuan bahasa dari satu bahasa ke bahasa lain untuk memperluas gaya bahasa atau ragam bahasa, pemakaian kata, klausa, idiom, sapaan dan sebagainya. Campur kode adalah istilah untuk penutur yang mencampur sedikitnya dua bahasa dalam suatu tindak bahasa tanpa adanya tuntutan dalam situasi bahasa tersebut untuk pencampuran bahasa (Nababan, 1984: 32). Menurut Rokhman (Ulfiani, 2014: 97) campur kode merupakan situasi penyisipan unsur 
bahasa antara dua bahasa atau lebih untuk memperluas gaya bahasa. Peristiwa pencampuran antara variasi bahasa yang berbeda dalam satu klausa dinamakan campur kode. Arni (2014:45) menjelaskan bahwa wujud penggunaan bahasa lainnya pada seseorang dwibahasa disebut dengan campur kode.

Campur kode (code mixing) terjadi apabila adanya penggunaan secara dominan suatu bahasa dan menyisipkan unsur bahasa lain untuk mendukung suatu tuturan. Biasanya, hal tersebut berhubungan dengan latar belakang penutur. Ciri menonjol yang ditunjukkan biasanya berupa situasi informal. Selain itu, campur kodejuga bisa terjadi karena keterbatasan bahasa, ungkapan yang tidak ada ada padanannya, sehingga terjadi keterpaksaan penyisipan unsur bahasa lain, walaupun hanya mendukung satu fungsi (Azhar, dkk., 2011: 16 - 17).

\section{b. Dwibahasa}

Menurut KBBI, dwibahasa adalah mampu memahami dan menggunakan dua bahasa; bilingual. Menurut Ohoiwutan (1007: 66), dwibahasa adalah penggunaan dua bahasa atau lebih oleh seorang individu. Jadi, dapat disimpulkan bahwa dwibahasa adalah sesorang yang menggunakan dua bahasa atau lebih.

\section{c. Identitas Nasional}

Identitas nasional merupakan suatu hal yang dapat menjadi jati diri atau ciri khas suatu bangsa. Istilah identitas nasional, secara etimologis berasal dari kata "identitas" dan "nasional". Dua kata tersebut berasal dari kata identity "memiliki tanda, ciri atau jati diri yang melekat pada suatu individu, kelompok atau sesuatu yang membedakannya dengan yang lain' dan nation 'bangsa'. Bangsa sendiri dalam Kamus Besar Bahasa Indonesia (KBBI) memiliki pengertian kelompok masyarakat yang bersamaan asal keturunan, adat, bahasa dan sejarahnya, serta berpemerintahan sendiri. Sedangkan, pengertian bangsa dalam lingkup politik memiliki arti masyarakat yang tundukk terhadap kedaulatan negaranya dan tinggal dalam suatu daerah yang sama. Pada hakikatnya, identitas nasional merupakan manifestasi nilai-nilai budaya yang tumbuh dan berkembang dalam aspek kehidupan suatu bangsa dengan ciri khas yang berbeda dengan bangsa lain (Srijanti, 2009).

Menurut Goebner (Erdward, 2009: 16), kata identitas merujuk pada kepemilikan yang bersifat subjektif sebagai klasifikasi penting bagi diri sendiri atau sebuah kelompok serta menjadi penanda yang dapat menggambarkan keanggotaan seseorang dalam sebuah kelompok. Seringkali seorang manusia tidak hanya memiliki satu identitas, tetapi bisa jadi memiliki lebih dari satu identitas ataupun satu identitas yang menyeluruh (terdiri dari berbagai identitas).

Berdasarkan hal tersebut, dapat disimpulkan bahwa setiap negara yang merdeka pasti memiliki identitas, termasuk Indonesia. Bangsa Indonesia memiliki beberapa alat pemersatu bangsa sebagai identitas nasional, salah satunya adalah bahasa Indonesia. Bahasa Indonesia memiliki kedudukan sebagai bahasa negara dan bahasa nasional. Hal tersebut menunjukkan bahwa bahasa Indonesia merupakan salah satu identitas bangsa. Jika bahasa Indonesia tidak digunakan dengan baik dan benar, maka identitas bangsa pun akan ikut terkikis.

\section{A. Faktor Pemengaruh Terjadinya Penggunaan Tindak Tutur Campur Kode}

Berdasarkan hasil penelitian, faktor pemengaruh penggunaan campur kode adalah sebagai berikut. 


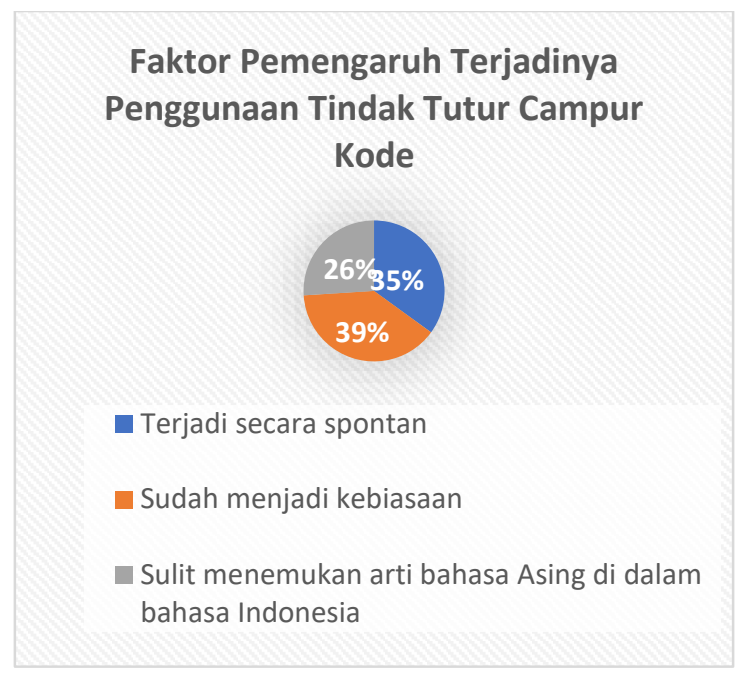

Berdasarkan data di atas, 35\% responden menyatakan bahwa tindak tutur campur kode dalam bertutur bahasa Indonesia disebabkan oleh kespontanan dan tanpa disadari, 39\% responden menyatakan penggunaan campur kode ini sudah menjadi kebiasaan, dan $26 \%$ responden menyatakan sulit menemukan arti dari bahasa Asing di dalam bahasa Indonesia. Dilihat dari data tersebut, penggunaan campur kode dipengaruhi oleh beberapa faktor, di antaranya terjadi secara spontan, sudah menjadi kebiasaan dan sulit menemukan arti bahasa Asing dalam bahasa Indonesia. 1) Terjadi secara spontan. Hal tersebut bisa terjadi dikarenakan faktor lingkungan yang sering menggunakan campur kode, kemudian tanpa sadar diikuti. 2) Sudah menjadi kebiasaan. Masyarakat bilingual yang terbiasa menggunakan dua bahasa akan tanpa sadar mencampurkan dua unsur bahasa menjadi satu, hal tersebut terus berulang, sehingga menjadi kebiasaan. 3) Sulit menemukan arti bahasa Asing dalam bahasa Indonesia. Ada banyak istilah Asing yang memang suit ditemukan artinya dalam bahasa Indonesia, biasanya bahasa tersebut cenderung baru dan dalam bahasa Indonesia belum ada artinya. Selain itu, banyak masyarakat yang menggunakan campur kode ini secara sengaja dengan anggapan hal tersebut dapat membantu mempelajari bahasa asing. Padahal, jika kita menggunakan sebuah bahasa tidak sesuai dengan kaidahnya, maka hal tersebut malah akan menghilangkan ciri khas dari bahasa itu sendiri. Selain itu, banyak masyarakat yang menggunakan campur kode ini hanya karena megikuti pergaulan, hal tersebut mengakibatkan rusaknya kaidah bahasa Indonesia karena dimasukkannya unsur-unsur bahasa lain yang tidak sesuai dengan tata aturan bahasa Indonesia. Pada akhirnya, tanpa sadar hal itu malah mengikis atau menghilangkan identitas bangsa. Suwito (1985: 78) berpendapat bahwa campur kode terjadi karena adanya hubungan timbal balik antara penutur, bentuk dan fungsi bahasa. Artinya penutur yang latar belakang sosial tertentu memberikan kecenderungan kepada penutur untuk memilih bentuk campur kode tertentu dengan tujuan mendukung fungsi-fungsi tertentu. Suandi (2014: 143146) berpendapat bahwa faktor penyebab terjadinya campur kode di antaranya adalah keterbatasan penggunaan kode, penggunaan istilah yang lebih populer, mitra bicara, kepribadian pembicara, tempat tinggal dan waktu pembicaraan, topik, tujuan, fungsi, ragam dan tingkat tutur bahasa, kehadiran penutur ketiga, inti pembicaraan, sebagai pembangkit rasa humor atau hanya sekadar bergengsi. 


\section{B. Pengaruh Penggunaan Campur Kode terhadap Identitas Bangsa}

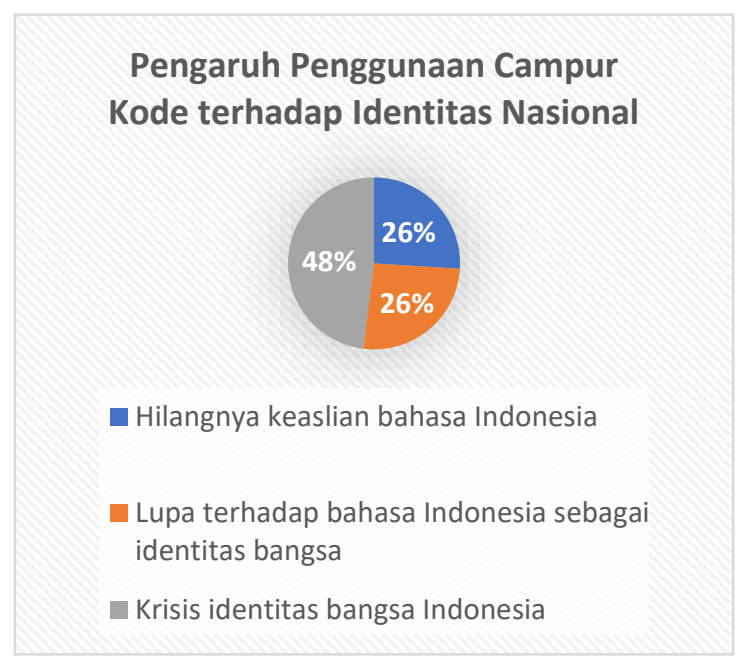

Berdasarkan diagram di atas, 26\% responden mengatakan jika campur kode digunakan hanya sekadar mengikuti lingkungan, maka akan berdampak pada hilangnya keaslian bahasa Indonesia, 26\% responden menyatakan bahwa percampuran dua unsur bahasa tersebut akan berdampak pada lupanya masyarakat terhadap bahasa Indonesia sebagai identitas bangsa, dan $40 \%$ responden lainnya menyatakan bahwa tindak tutur campur kode yang hanya mengikuti lingkungan ini akan menjadikan bangsa Indonesia mengalami krisis identitas nasional.

Penggunaan campur kode dalam bertutur bahasa Indonesia memang pada dasarnya untuk memperluas gaya bahasa seperti definisi dari campur kode itu sendiri yaitu penggunaan satuan bahasa dari satu bahasa ke bahasa lain untuk memperluas gaya bahasa. Fasold (dalam Soshum Jurnal dan Humaniora, 2017) mengatakan bahwa terjadinya campur kode adalah ketika seseorang menyisipkan satu kata atau frase dari satu bahasa ke dalam bahasa lainnya. Hal ini layak terjadi jika memang seseorang memiliki keterbatasan dalam berbahasa, ungkapan dalam bahasa tersebut tidak ada padanannya dalam bahasa Indonesia sehingga menyebabkan adanya keterpaksaan memasukkan unsur bahasa lain. Tetapi, lain halnya jika hanya mengikuti pergaulan dan tanpa mementingkan identitas dari bahasa Indonesia itu sendiri, maka bahasa Indonesia semakin lama akan semakin memudar, begitu pula dengan identitas nasional.

Dalam kajian sosiolinguistik, bahasa tidak hanya dilihat sebagai sebuah sistem bunyi, tetapi juga dapat dilihat sebagai bagian yang melekat dan tidak dapat terpisahkan dari manusia dan masyarakat. Edward (2009: 54) menyebut ada hal lain dari bahasa selain fungsinya sebagai alat untuk berkomunikasi. Artinya, adanya hubungan lain dalam bahasa yang menunjukan adanya hubungan bahasa dengan identitas. Lebih lanjut, Edward (2009: 21) juga mengatakan bahwa bahasa dapat dianggap sebagai ciri/penanda seseorang. Berdasarkan hal tersebut, identitas nasional ini harus dijaga agar jati diri bangsa Indonesia tidak luntur. Selain menjadi ciri khas suatu bangsa, identitas nasional ini merupkan sebuah alat pemersatu bangsa.

\section{KESIMPULAN}

Penggunaan campur kode dalam bertutur bahasa Indonesia masih banyak terjadi. Terjadinya tindak tutur campur kode disebabkan oleh banyak faktor, baik faktor internal maupun eksternal. Jika campur kode terjadi karena memang seseorang memiliki keterbatasan bahasa, tidak ada padanan dari ungkapan dalam bahasa tersebut, sehingga ada keterpaksaan memasukkan unsur bahasa lain, maka itu adalah hal yang wajar. Tetapi, lain halnya jika hanya mengikuti pergaulan dan tanpa mementingkan identitas dari bahasa Indonesia itu sendiri, maka bahasa Indonesia semakin lama akan semakin memudar dan akan mengikis identitas nasional. Oleh karena itu, kita harus menjaga bahasa Indonsia agar jati diri bangsa Indonesia tidak luntur. 


\section{DAFTAR PUSTAKA}

Devinna Riskiana Aritonang, d. (2019). PENGEMBANGAN KOSA KATA MELALUI KETERAMPILAN MENULIS . LINGUISTIK : Jurnal Bahasa \& Sastra Vol.4 No.2.

Fajar Eka Bintara, K. S. (2017). ALIH KODE DAN CAMPUR KODE DALAM PEMBELAJARAN . Jurnal Penelitian Bahasa, Sastra Indonesia dan Pengajarannya Volume 5 Nomor 1, 78.

MARNI, W. O. (2016). CAMPUR KODE DAN ALIH KODE DALAM PERISTIWA . Jurnal Bastra Vol. 2 No. 1.

Mira Oktaria, d. (n.d.). ALIH KODE DAN CAMPUR KODE PADA PEMBELAJARAN . Jurnal Kata (Bahasa, Sastra, dan Pembelajarannya).

Muhammad Yusnan, d. (2020). ALIH KODE DAN CAMPUR KODE PADA NOVEL BADAI MATAHARI . Uniqbu Journal Of Social Sciences (UJSS), 1-12.

Rulyandi, M. R. (2014). ALIH KODE DAN CAMPUR KODE DALAM. Jurnal Paedagogia, Vol. 17 No. 1, 27-38.

Siti Rohmani, A. F. (2013). ANALISIS ALIH KODE DAN CAMPUR KODE. Jurnal Penelitian Bahasa, Sastra Indonesia dan Pengajarannya Volume 2 Nomor 1, 2-4.

Susmita, N. (2015). ALIH KODE DAN CAMPUR KODE DALAM PEMBELAJARAN. Jurnal Penelitian Universitas Jambi Seri Humaniora, 87-98.

Sutarma, I. G. (2017). CAMPUR KODE DALAM PENGGUNAAN BAHASA INDONESIA . SOSHUM JURNAL SOSIAL DAN HUMANIORA, VOL.8, NO.2, 190-191.

Yuniati, I. (2018). ALIH KODE DAN CAMPUR KODE DALAM PENGAJARAN BAHASA INDONESIA KELAS XI SMAN 6 KABUPATEN BENGKULU TENGAH. LP4MK STKIP PGRI LUBUKLINGGAU Vol. 1, No. 1, 47-65.

Zuhriyah, D. K. (2017). ALIH KODE DAN CAMPUR KODE. Journal Indonesian Language Education and Literature Vol. 3, No. 1, 53-64. 